\title{
Efficient hydrothermal deoxygenation of tall oil fatty acids into n-paraffinic hydrocarbons and alcohols in the presence of aqueous formic acid
}

\author{
Lakhya Jyoti Konwar $^{1} \cdot$ Benedetta Oliani ${ }^{2}$ - Ajaikumar Samikannu ${ }^{1} \cdot$ Paolo Canu ${ }^{2} \cdot$ Jyri-Pekka Mikkola ${ }^{1,3}$
}

Received: 18 May 2020 /Revised: 13 July 2020 / Accepted: 22 October 2020 / Published online: 5 November 2020

(C) The Author(s) 2020

\begin{abstract}
Hydrothermal deoxygenation of tall oil fatty acids (TOFA) was investigated in the presence of aqueous formic acid (0.5-7.5 wt $\%$ ) as a $\mathrm{H}_{2}$ donor in the presence of subcritical $\mathrm{H}_{2} \mathrm{O}$ pressure (569-599 K). Pd and Ru nanoparticles supported on carbon (5\% $\mathrm{Pd} / \mathrm{CS}$ igma, 5\% Ru/CSigma, 10\% Pd/CO850_DP, and 5\% Ru/COPcomm_DP) were found to be efficient catalysts for deoxygenation of TOFA. The reaction pathway was mainly influenced by the concentration of formic acid and the catalyst. In case of Pd catalysts, in the presence of $0-2.5 \mathrm{wt} \%$ formic acid, decarboxylation was the dominant pathway producing $\mathrm{n}$-paraffinic hydrocarbons with one less carbon atom (heptadecane yield up to $94 \mathrm{wt} \%$ ), while with $5-7.5 \%$ formic acid, a hydrodeoxygenation/hydrogenation mechanism was favored producing C18 deoxygenation products octadecanol and octadecane as the main products (yields up to $70 \mathrm{wt} \%$ ). In contrast, Ru catalysts produced a mixture of C5-C20 (n-and isoparaffinic) hydrocarbons via decarboxylation, cracking and isomerization (up to $58 \mathrm{wt} \% \mathrm{C} 17$ yield and total hydrocarbon yield up to $95 \mathrm{wt} \%$ ) irrespective of formic acid concentration. Kinetic studies showed that the rates of deoxygenation displayed Arrhenius type behavior with apparent activation energies of $134.44 \pm 31.36 \mathrm{~kJ} / \mathrm{mol}$ and $148.92 \pm 3.66 \mathrm{~kJ} / \mathrm{mol}$, for the $5 \% \mathrm{Pd} /$ CSigma and $5 \% \mathrm{Ru} / \mathrm{CSigma}$ catalyst, respectively. Furthermore, the experiments with glycerol tristearate, rapeseed oil, sunflower oil, rapeseed biodiesel, and hydrolyzed rapeseed oil produced identical products confirming the versatility of the aforementioned catalytic systems for deoxygenation of $\mathrm{C} 18$ feedstocks.
\end{abstract}

Keywords Hydrothermal deoxygnation · Supported carbon catalysts · Transfer hydrogenation · Green diesel

Supplementary Information The online version contains supplementary material available at https://doi.org/10.1007/s13399-02001103-3.

\footnotetext{
Lakhya Jyoti Konwar

lakkhya07@gmail.com

$\triangle$ Jyri-Pekka Mikkola

jyri-pekka.mikkola@umu.se

1 Technical Chemistry, Department of Chemistry,

Chemical-Biological Centre, Umeå University, SE-901

87 Umeå, Sweden

2 Department of Industrial Engineering, University of Padova, Via F. Marzolo, 9, 35131 Padova, Italy

3 Laboratory of Industrial Chemistry and Reaction Engineering, Johan Gadolin Process Chemistry Centre, Åbo Akademi University, FI-20500 Turku, Finland
}

\section{Introduction}

The use of renewables for the production of energy, fuels, and chemicals (biorefining) has gained considerable attention during the recent years due to the shrinking petroleum reserves, unstable market fluctuations in its price, and associated environmental hazards caused by their use. Various biomasses have been identified as alternate sources of energy fuels and among them lipids, fats, and oils derived from plant and animal sources have been regarded as the most attractive source for production of alternative fuels. In 2009-2010, the global production of vegetable oils was close to $140,000,000$ metric tonnes, out of which approximately $20 \%$ was diverted for non-food applications such as production of biofuels (biodiesel and hydrogenated vegetable oil), biolubricants, and chemicals. Global production of oleochemicals was in 2009 amounting to 7.7 million tonnes of fatty acids and 2,000,000 tonnes of fatty alcohols, while fatty acid methyl ester 
(biodiesel) production was close to $14,000,000$ tonnes [1-3]. To summarize, it remains an undeniable fact that chemically "fats and oils" are one of the most promising feedstocks upon production of "drop-in" fuels and chemicals suitable for substituting many of the petroleum-based products currently in use $[4,5]$.

Fats and oils are easily converted into fatty acid methyl esters (FAME), a product commonly known as biodiesel by the well-known transesterification and/or esterification reactions involving reaction of fats and oils with a monohydric alcohol such as methanol in the presence of an acid, alkali, or enzyme catalyst (depending on FFA content of oil) [1-3]. Nevertheless, its use has several drawbacks, especially with regard to fuel quality (viscosity, low energy density, strong solvent properties, etc.) and storage stability (oxidative fouling, algae growth). Due to these shortcomings, the use of biodiesel in existing diesel engines has often been limited to low volumetric percentage (5-7\%) with petroleum diesel [6]. To overcome such limitations, alternative routes have been developed to convert fats and oils into diesel-like hydrocarbons (green diesel or renewable diesel) [5]. Among these, catalytic cracking, hydrocracking, and hydroprocessing (hydrocracking/hydrodeoxygenation and decarboxylation) have been extensively studied; the latter technology has been successfully commercialized (Neste NExBTL and UPM, UPM BioVerno) [7-9]. The hydrotreating/hydroprocessing (HDO) pathway includes the processing of triglycerides and fatty acids at $300-450{ }^{\circ} \mathrm{C}$ over a heterogeneous catalyst with a high $\mathrm{H}_{2}$ partial pressures between 4 and $15 \mathrm{MPa}$ [10]. The initial hydrogenation step saturates the olefinic and acetylenic fatty acid chains followed by subsequent deoxygenation through hydrodeoxygenation, decarbonylation and decarboxylation reactions into a mixture of paraffinic hydrocarbon with chain lengths between $\mathrm{C} 15$ and $\mathrm{C} 18$. The process also produces $\mathrm{C} 1-$ $\mathrm{C} 4$ gaseous by-products $\left(\mathrm{CO}, \mathrm{CO}_{2}, \mathrm{H}_{2} \mathrm{O}\right)$ and $\mathrm{C} 1-\mathrm{C} 4$ hydrocarbons (such as methane, propane, butane). The hydrotreatment process is typically based on sulfided catalysts such as NiMo ( $\mathrm{NiMo} / \mathrm{Al}_{2} \mathrm{O}_{3}, \mathrm{NiMo} /$ zeolite) and supported novel metal ( $\mathrm{Pt}, \mathrm{Pd}$, and $\mathrm{Ni}$ ) catalysts. In addition to this, the hydrotreatment process also requires a high $\mathrm{H}_{2}$ partial pressure, high $\mathrm{H}_{2}$-to-triglyceride ratio up to $1000: 1$ and long sulfidation time to effectively remove oxygen functionalities as $\mathrm{H}_{2} \mathrm{O}[5,11,12]$. The use of sulfiding agent feeding and $\mathrm{H}_{2}$ to-triglyceride ratios up to 1000:1 are also essential to enhance catalyst stability and reduce the formation of cycloalkane and aromatic byproducts $[13,14]$. The large $\mathrm{H}_{2}$ requirement also affects the environmental sustainability of the process (since $\mathrm{H}_{2}$ is typically produced from fossil-based methane steam reforming). Decarboxylation is an alternative deoxygenation route in which oxygen is removed from the fatty acid chains as $\mathrm{CO}_{2}$ rather than $\mathrm{CO}$ and $\mathrm{H}_{2} \mathrm{O}$, most importantly the process requires no net $\mathrm{H}_{2}$ to convert the saturated fatty acids (lauric, palmitic, stearic acid, etc.) [15]. On the other hand, the decarboxylation of unsaturated fatty acids (palmitoleic, oleic, linoleic, etc.) requires only a small, stoichiometric amount of $\mathrm{H}_{2}$ to saturate the olefinic and acetylenic bonds. Supported metal catalysts based on noble metals (Pt, Pd, Rh, Ru, Ni, and Ir) are reported as the most plausible catalysts for decarboxylation where upon the activity and selectivity are influenced by both the nature of metal and support. The reaction typically requires a low-boiling organic solvent like dodecane or mesitylene to afford improved fluidity, mass transfer and prevent catalyst deactivation $[16,17]$. Hydrothermal decarboxylation is a related deoxygenation process in which the deoxygenation is achieved in the presence of sub or supercritical water $\left(300-400{ }^{\circ} \mathrm{C}\right.$ and $50-220$ bar), in the presence of a suitable metal catalyst. Water becomes a highly reactive reaction medium thanks to its reduced dielectric constant and the increase of interphase mass transfer leading to an improved solubility with non-polar reactants [10, 18-22]. Pt, $\mathrm{Pd}, \mathrm{Ni}$, and $\mathrm{Cu}$ catalysts supported on hydrothermally stable supports like activated carbon and $\mathrm{ZrO}_{2}$ are reported to be effective catalysts for hydrothermal decarboxylation; activated carbon has also been reported to be a effective catalyst at 380-400 ${ }^{\circ} \mathrm{C}$ under supercritical conditions (220 bar) [23-25]. As a matter of fact, due to the low hydrogen requirement and favorable dehydrogenation conditions (aqueous phase reforming), hydrothermal decarboxylation has also been demonstrated to be efficient with in situ generated hydrogen (catalytic transfer hydrogenation) for production of diesel-like hydrocarbons from fats and oils [26-28]. As an example, $\mathrm{Li}$ et al. demonstrated that by combining catalytic transfer hydrogenation with hydrothermal deoxygenation, it is possible to reduce the reaction temperatures by $120{ }^{\circ} \mathrm{C}$; using decalin and dodecane as hydrogen donors $(9: 1 \mathrm{v} / \mathrm{v}$ of decalin/ dodecane: $\mathrm{H}_{2} \mathrm{O}$ ) upon hydrothermal deoxygenation of triglycerides with $\mathrm{Pd} / \mathrm{C}$ catalyst (71.9\% hydrocarbon yield in $12 \mathrm{~h}$ ) [28].

Formic acid is considered as a safe and promising candidate for hydrogen storage due to its low toxicity, stability, and ease of transportation and handling. Formic acid has also been demonstrated as a powerful hydrogen donor for hydrogenation or deoxygenation reactions in the presence of suitable catalysts ( $\mathrm{Pd}, \mathrm{Pt}$, and $\mathrm{Ru})$. Supercritical water has also been reported to catalyze the decomposition of formic acid to $\mathrm{H}_{2}$ and $\mathrm{CO}_{2}$. The latter, in particular, has potential for application in aqueous phase processing of oxygenated biomolecules into high-value products like synthetic hydrocarbons. The application of formic acid provides the great advantage over molecular hydrogen that it is much easier and safer to store and transport formic acid $[29,30]$. Keeping the above points in mind, the present study was undertaken with the aim of investigating hydrothermal decarboxylation/deoxygenation of TOFA and related fatty acid derivatives in the presence of aqueous formic acid with carbon supported $\mathrm{Pd}$ and $\mathrm{Ru}$ catalysts. 


\section{Experimental}

\subsection{Materials and methods}

Activated carbon (powder, Fisher Scientific), formic acid ( $\mathrm{HCOOH}$, Sigma, 99\%), stearic acid $\left(\mathrm{C}_{18} \mathrm{H}_{36} \mathrm{O}_{2}\right.$, ACROS Organics, $97 \%$ ), glyceryl tristearate $\left(\left[\mathrm{CH}_{3}\left(\mathrm{CH}_{2}\right)_{16} \mathrm{COOCH}_{2}\right]_{2} \mathrm{CHOCO}\left(\mathrm{CH}_{2}\right)_{16} \mathrm{CH}_{3}\right.$, Sigma, technical grade), palmitic acid $\left(\mathrm{C}_{16} \mathrm{H}_{32} \mathrm{O}_{2}\right.$, Sigma, $\left.\geq 99 \%\right)$, heptadecane $\left(\mathrm{C}_{17} \mathrm{H}_{36}\right.$, Sigma, 99\%), 1-octadecanol $\left(\mathrm{C}_{18} \mathrm{H}_{38} \mathrm{O}\right.$, Sigma, 99.5\%), n-octadecane $\left(\mathrm{C}_{18} \mathrm{H}_{38}\right.$, Sigma, 99.9\%), C7-C30 saturated alkanes standard (Sigma, $1000 \mu \mathrm{g} / \mathrm{ml}$ in hexane), dichloromethane $\left(\mathrm{CH}_{2} \mathrm{Cl}_{2}\right.$, Sigma, $\left.99 \%\right)$, palladium chloride $\left(\mathrm{PdCl}_{2}\right.$, Sigma, $59 \% \mathrm{Pd})$, ruthenium chloride $\left(\mathrm{RuCl}_{3} \cdot \mathrm{xH}_{2} \mathrm{O}\right.$, abcr $\mathrm{GmbH}, 36 \%$ $\mathrm{Ru})$, nickel nitrate $\left(\mathrm{Ni}\left(\mathrm{NO}_{3}\right)_{2} \cdot 6 \mathrm{H}_{2} \mathrm{O}\right.$, Sigma, $\left.99 \%\right)$, and hydrochloric acid ( $\mathrm{HCl}$, Merck, 37\%) were obtained from commercial sources and used without further purifications. Tall oil fatty acid (TOFA, FOR2x_004, $193 \mathrm{mgKOH} / \mathrm{g}$ ) was supplied by Forchem Oy, Finland. Food grade rapeseed and sunflower oil were procured from a local supermarket and used as received. Hydrolyzed rapeseed oil and rapeseed fatty acid methyl esters (FAME) were produced by the standard acid hydrolysis and transesterification method. The fatty acid composition of the different feedstocks utilized in this study has been summarized in Table 1 .

\subsection{Catalytic materials}

The commercial palladium (5\% Pd/CSigma) and ruthenium (5\% Ru/CSigma) catalysts were obtained from Sigma Aldrich and used as received. Raney Nickel was obtained from Grace and used as received. The 10\% Pd/CO850_DP, 5\% Ru/ COPcomm_DP, and $15 \% \mathrm{Ni} /$ COPcomm_IW catalysts were prepared by the well-known deposition precipitation method using either KOH-activated carbon (CO850, $1527 \mathrm{~m}^{2} / \mathrm{g}, 0.85$ $\mathrm{cm}^{3} / \mathrm{g}$, produced in house) or commercial-activated carbon from fisher as the carrier $\left(1336 \mathrm{~m}^{2} / \mathrm{g}, 1.38 \mathrm{~cm}^{3} / \mathrm{g}\right.$, produced in house) $[31,32]$. The synthesis procedure for catalytic materials was as follows: $0.5 \mathrm{~g} \mathrm{KOH}$-activated carbon was added to $25 \mathrm{ml}$ deionized water under stirring at room temperature. After stirring for $15 \mathrm{~min}$, an appropriate amount of $\mathrm{PdCl}_{2}$ (84.6 $\mathrm{mg}$ in $40 \mathrm{ml} 1 \mathrm{M} \mathrm{HCl})$ or $\mathrm{RuCl}_{3}(69.4 \mathrm{mg} 40 \mathrm{ml}$ in deionized water) solution was added and stirred for $2 \mathrm{~h}$. In the next step, $\mathrm{pH}$ of the resulting solution adjusted to 9.5 by slow addition of $0.1 \mathrm{M} \mathrm{NaOH}$. After stirring for $1 \mathrm{~h}$, a calculated amount of freshly prepared $\mathrm{NaBH}_{4}$ solution $\left(\mathrm{nNaBH}_{4} /\right.$ nMetal $=15 / 1)$ was rapidly added into the solution. The resulting mixture was further stirred for $1 \mathrm{~h}$ at room temperature, filtered, and extensively washed with deionized water until free from $\mathrm{Cl}^{-}$ions $\left(\mathrm{AgNO}_{3}\right.$ test). The resulting catalytic materials were dried under a stream of $\mathrm{N}_{2}$ at $70{ }^{\circ} \mathrm{C}$ and stored in a desiccator prior to use. The $15 \% \mathrm{Ni} / \mathrm{COPcomm}$ IW catalyst was prepared using the incipient-wetness impregnation method. First, the commercial activated carbon $\left(1336 \mathrm{~m}^{2} / \mathrm{g}\right.$, $1.38 \mathrm{~cm}^{3} / \mathrm{g}$ ) carrier was evacuated at $100{ }^{\circ} \mathrm{C}$ and added to a solution of $\mathrm{Ni}\left(\mathrm{NO}_{3}\right)_{2} \cdot 6 \mathrm{H}_{2} \mathrm{O}$ to achieve $15 \% \mathrm{Ni}$ lading. Prior to use, the resulting sample were dried at $105{ }^{\circ} \mathrm{C}$ in an oven overnight, followed by thermal annealing at $300{ }^{\circ} \mathrm{C}$ for $2 \mathrm{~h}$ and reduction with $5 \% \mathrm{H}_{2}$ in $\mathrm{N}_{2}$ for $3 \mathrm{~h}$ at $400{ }^{\circ} \mathrm{C}$. The actual $\mathrm{Pd}, \mathrm{Ru}$, and Ni loadings, measured by ICP-OES elemental analysis, were found to be identical to the designed loadings in all the catalysts.

\subsection{Characterization of catalytic materials}

The specific surface area, pore size, and pore volume of the catalytic materials were determined by liquid $\mathrm{N}_{2}$ physisorption on a Micromeritics TriStar 3000 porosimeter. Adsorption-desorption isotherms were recorded at $-196{ }^{\circ} \mathrm{C}$ after the samples were outgassed at $150{ }^{\circ} \mathrm{C}$ for $3 \mathrm{~h}$. The specific surface areas were calculated by the BET method, and the pore volumes were calculated from desorption isotherms. The pore size distributions were estimated using the Barrett, Joyner, and Halenda (BJH) algorithm (ASAP-2010) available as a built in software from micromeritics. Transmission electron microscopy (TEM) images were recorded on a Jeol JEM2100 electron microscope operating at $200 \mathrm{kV}$. The resolution was around $0.4 \mathrm{~nm}$. Samples were suspended in ethanol and deposited on a copper grid for analysis. The metal particle dispersion, metal surface area, and metal particle sizes were obtained from $\mathrm{H}_{2}$ pulse chemisorption on a BELCAT II instrument (MicrotracBEL Corp.) equipped with TCD detector. For dynamic $\mathrm{H}_{2}$ pulse chemisorption measurements, 20-50 mg pre-reduced sample was placed in an adsorption vessel and similarly evacuated at $100{ }^{\circ} \mathrm{C}$ for $2 \mathrm{~h}$ under $50 \mathrm{ml} / \mathrm{min}$ $\mathrm{Ar}$ flow in order to remove adsorbed gases. After cooling to adsorption temperature, $800 \mu \mathrm{L}$ pulses of $5 \% \mathrm{H}_{2}$ in Ar were
Table 1 Fatty acid composition of the different feedstocks used in the study

\begin{tabular}{llll}
\hline Fatty acid & TOFA & Rapeseed oil/FAME and FFA & Sunflower oil \\
\hline Palmitic (wt\%) & 0 & 5.3 & 6.38 \\
Stearic (wt\%) & 1.56 & 23.5 & 3.15 \\
Oleic (wt\%) & 40.78 & 51.9 & 30 \\
Linoleic (wt\%) & 46.97 & 15.6 & 60 \\
$\gamma$-Linolenic (wt\%) & 10.67 & 3.6 & 0 \\
\hline
\end{tabular}


passed through the sample. The adsorption temperature was set at $100{ }^{\circ} \mathrm{C}$ for Ru and at $35^{\circ} \mathrm{C}$ for Pt- and Pd-based catalysts. The catalyst weight and pulse volume used were chosen in such a way as to allow the injection of several pulses before the catalyst was saturated. Table 2 summarizes some of the important textural and catalytic properties of the supported carbon catalysts utilized in this work, while XRD patterns of select catalyts are presented in Figure S1, supporting information.

\subsection{Catalytic reaction procedures}

All catalytic reactions were carried out in stainless steel mini batch reactors ( $\sim 14 \mathrm{~mL}$ volume) assembled from 3/4-inch tube and 3/4-inch caps purchased from Swagelok. The amount of deionized water (solvent) was fixed in such a way that the water occupied ca. $70 \%$ of the total reactor volume in saturation/reaction conditions (steam pressure of ca. $35 \pm$ 5 bar was observed experimentally with 5 bar, measured using a modified setup equipped with a pressure gauge and inlet/ outlet valves). The amount of water was reduced to compensate for the extra pressure generated due to decomposition of formic acid into $\mathrm{H}_{2}$ and $\mathrm{CO}_{2}$. The quantity of reactant (TOFA and related $\mathrm{C} 18$ feedstock) was fixed at $3 \%$ with respect to water while catalyst loading was fixed at $18 \mathrm{wt} \%$ of reactant. The weight percentage of formic acid was varied in the range of $0-7.5 \mathrm{wt} \%$ with respect to water $[18,19]$. In a typical reaction, the reactor was loaded with desired amount of catalyst, tristearin, and water, carefully weighed and placed inside a preheated oven (Nabetherm B180) at $373 \mathrm{~K}$ for $30 \mathrm{~min}$ (to ensure uniform melting of tristearin). To initiate reaction, the autoclaves were heated to the final reaction temperature (569-
$599 \mathrm{~K}$, heating rate $\sim 3.6^{\circ} \mathrm{C} / \mathrm{min}$ ) and held at this temperature between 5 and $240 \mathrm{~min}$. As soon as the desired reaction time was reached, the reactor was removed from the furnace and quickly quenched with ice cold water. The reactor was opened and slowly depressurized and weighed; afterwards, the aqueous phase was transferred to a centrifuge tube and the reactor thoroughly rinsed with $3 \mathrm{~mL}$ of dichloromethane. After thorough mixing and centrifugal separation at $7500 \mathrm{rpm}$, the lower phase (composed of hydrocarbons, stearic acid, and dichloromethane) was sampled. The liquid products were analyzed on a GC-FID (Agilent 7820A) equipped with a DB-5MS column; in some instances, a HP-innowax column was also used as it afforded a better separation of oxygenated products. Occasionally, gaseous products were collected and analyzed by GC-MS (Agilent 5579N) equipped with a DB-5MS column, to allow gaseous product sampling reactions were performed in the modified setup equipped with pressure gauge and inlet/outlet valves using 5 bar $\mathrm{N}_{2}$ as balance gas. The liquid range reaction products (heptadecane, octadecane, 1octadecanol, stearic acid, and C5-C15 alkanes) were identified by comparing the gas chromatograph retention times with standard compounds. Quantitative analysis of these compounds was carried out using standard calibration curves. The GC response was linear in all the concentration range for each component. The conversion and product yield are defined as follows:

$$
\begin{aligned}
& \text { Conversion }(\%)=\frac{C_{0}-C_{t}}{C_{0}} \times 100 \\
& \operatorname{yield}(\%)=\frac{C_{\text {product }}}{C_{0}} \times 100
\end{aligned}
$$

Table 2 Properties of catalytic

\begin{tabular}{|c|c|c|c|c|c|c|c|}
\hline Catalyst & $\begin{array}{l}{ }^{\mathrm{a}} \text { Metal } \\
\text { loading } \\
(\mathrm{wt} \%)\end{array}$ & $\begin{array}{l}\text { Specific } \\
\text { surface area } \\
\left(\mathrm{m}^{2} / \mathrm{g}\right)\end{array}$ & $\begin{array}{l}\text { Pore volume } \\
\text { area }\left(\mathrm{cm}^{3} / \mathrm{g}\right)\end{array}$ & $\begin{array}{l}\text { Pore } \\
\text { size } \\
(\mathrm{nm})\end{array}$ & $\begin{array}{l}{ }^{\mathrm{b}} \mathrm{D} \\
(\%)\end{array}$ & $\begin{array}{l}{ }^{b} d_{p, H 2} \\
(\mathrm{~nm})\end{array}$ & $\begin{array}{l}{ }^{\mathrm{c}} \mathrm{H}_{2} \text { uptake } \\
(\mathrm{mmol} / \mathrm{g})\end{array}$ \\
\hline 5\% Pd/CSigma & 5 & 929 & 0.81 & 3.5 & 28.7 & 3.91 & 1.35 \\
\hline $5 \% \mathrm{Ru} / \mathrm{CSigma}$ & 5 & 754 & 0.74 & 3.9 & 53.9 & 2.47 & 4.96 \\
\hline $\begin{array}{l}10 \% \\
\text { Pd/CO850_ } \\
\text { DP }\end{array}$ & 10 & 1219 & 0.77 & 2.5 & 22.6 & 4.96 & 1.35 \\
\hline $\begin{array}{l}5 \% \\
\quad \mathrm{Ru} / \mathrm{COP} \mathrm{Co}- \\
\mathrm{mm} \text { _DP }\end{array}$ & 5 & 1280 & 1.12 & 3.98 & 34 & 3.90 & 4.18 \\
\hline $\begin{array}{l}15 \% \\
\text { Ni/COPcom- } \\
\text { m_IW }\end{array}$ & 17 & 777 & 0.71 & 3.6 & n.d & n.d & n.d \\
\hline Raney Nickel & n.d & n.d & n.d & n.d & n.d & n.d & n.d \\
\hline
\end{tabular}
materials used in the work
${ }^{\text {a }}$ Based on ICP-OES

${ }^{\mathrm{b}}$ Based on $\mathrm{H}_{2}$ pulse chemisorption, where $D=$ dispersion and $\mathrm{d}_{\mathrm{p}, \mathrm{H} 2}=$ average metal particle size

${ }^{\mathrm{c}}$ Based on $\mathrm{H}_{2}$ consumption in TPR $\left(25-500{ }^{\circ} \mathrm{C}\right)$

n.d, not determined 
where $c_{\mathrm{o}}$ and $c_{t}$ represent the initial and final concentration of reactant (TOFA), and $c_{\text {product }}$ denotes the concentration of the product formed in $\mathrm{g} / \mathrm{L}$. However, since the tristearin was readily hydrolyzed during the initial heating (ramping), the catalyst performance was expressed in terms of specific rate of formation of deoxygenation products (hydrocarbons), by normalizing the initial rate of formation of hydrocarbon with the number of metal sites loaded into the reactor.

\section{Results and discussion}

\subsection{Catalysts screening for formic acid-assisted hy- drothermal deoxygenation of TOFA}

Results of preliminary catalytic activity tests conducted upon TOFA deoxygenation in the presence of $2.5 \mathrm{wt} \%$ aqueous formic acid solutions with the different metal catalysts are presented in Table 3 . The data presented in Table 3 clearly demonstrate the superior deoxygenation activity of the carbon supported $\mathrm{Ru}$ and $\mathrm{Pd}$ catalysts producing hydrocarbons in excellent yields (72-100 wt \%). In contrast, the Ni-based catalysts were inactive in the deoxygenation of TOFA with ca. tenfold low deoxygenation rates, producing the hydrogenated intermediate stearic acid, as the main reaction product. Furthermore, based on the data presented in Table 3, the Pd catalysts supported on carbon were clearly more active than the Ru-based catalysts upon TOFA deoxygenation. The order of catalytic activity based on specific rate of deoxygenation (mol.min ${ }^{-1} \mathrm{~g}_{\mathrm{M}}$ ) was as follows: $5 \% \mathrm{Pd} / \mathrm{CSigma>} 5 \% \mathrm{Ru} /$
CSigma $>5 \% \mathrm{Ru} /$ COPcomm DP $>10 \% \mathrm{Pd} / \mathrm{CO} 850 \mathrm{DP}>>$ $15 \% \mathrm{Ni} /$ COPcomm IW $>>$ Raney Nickel. The observed trend was consistent with the previously reported trends of decarboxylation activity $(\mathrm{Pt}>\mathrm{Pd}>\mathrm{Ru}>\mathrm{Ni}$ ) under non-hydrothermal as well as hydrothermal conditions [15-22]. Under similar process conditions, control experiments with the active carbon support and blank reaction (no catalyst) failed to produce measurable yields deoxygenated products in agreement with the important role of metal ( $\mathrm{Ru}, \mathrm{Pd}$, and $\mathrm{Ni}$ ) nanoparticles as active sites and similar to the previous findings of $\mathrm{Fu}$ and Savage et al. [18-21]. Among the tested catalytic materials, the commercial 5\% Pd/CSigma and 5\% Ru/CSigma were the most effective deoxygenation catalysts and afforded total hydrocarbon yields up to $>99.5 \mathrm{wt} \%$ and $82 \mathrm{wt} \%$, respectively in a short residence (batch holding) time of $120 \mathrm{~min}$. The superior activity of the commercial catalysts $(5 \% \mathrm{Pd} / \mathrm{CSigma}$ and $5 \% \mathrm{Ru} / \mathrm{CSigma}$ ) could be attributed to the presence of highly dispersed and small metal ( $\mathrm{Pd}$ and $\mathrm{Ru}$ ) nanoparticles (Table 2). However, our results are slightly different from the findings of Savage et al. indicating Pd and Pt to be good catalysts for palmitic acid deoxygenation only under near-or supercritical water conditions $[18,19]$. In this work, Pd as well as Ru nanoparticles on carbon was demonstrated to be active for deoxygenation under much milder process conditions (steam pressure of ca. $35 \pm 5$ bar). In fact, a negative effect was observed upon decarboxylation/deoxygenation activity with increased $\mathrm{H}_{2}$ and $\mathrm{CO}_{2}$ partial pressure (increased formic acid concentration) (see, section 3.3). The Ru catalysts also produced ca. $29 \%$ cracking hydrocarbons (Table 3). The differences observed in results of this work with those of Savage

Table 3 Initial rate, specific rate, conversion, and yield of liquid organic products obtained upon formic acid-assisted TOFA hydrothermal deoxygenation

\begin{tabular}{|c|c|c|c|c|c|c|c|c|}
\hline \multirow[t]{2}{*}{ Catalyst } & \multirow[t]{2}{*}{${ }^{\mathrm{a}}$ Initial rate $\left(\mathrm{mol} \cdot \mathrm{min}^{-1}\right)$} & \multirow[t]{2}{*}{${ }^{\mathrm{b}}$ Specific rate $\left(\mathrm{mol} \cdot \mathrm{min}^{-1} \cdot \mathrm{g}_{\mathrm{M}}\right)$} & \multirow[t]{2}{*}{ Time (min) } & \multirow[t]{2}{*}{ Conv. $(\%)$} & \multicolumn{4}{|c|}{ Composition of liquid product (wt\%) } \\
\hline & & & & & ${ }^{\mathrm{c}}$ Total HC & ${ }^{\mathrm{d}} \mathrm{C} 17 \mathrm{HC}$ & ${ }^{\mathrm{e}}$ Acids & ${ }^{\mathrm{f}}$ Alcohol \\
\hline $5 \% \mathrm{Pd} / \mathrm{CSigma}$ & $1.52 \times 10^{-5}$ & $8.92 \times 10^{-3}$ & 120 & 100 & $>99.5$ & 91 & 0 & 0 \\
\hline $5 \% \mathrm{Ru} / \mathrm{CSigma}$ & $8.74 \times 10^{-6}$ & $5.14 \times 10^{-3}$ & 120 & 100 & 82 & 53 & 18 & 0 \\
\hline 10\% Pd/CO850_DP & $4.64 \times 10^{-6}$ & $1.36 \times 10^{-3}$ & 180 & 100 & 100 & 92 & 0 & 0 \\
\hline $5 \%$ Ru/COPcomm_DP & $3.09 \times 10^{-6}$ & $1.82 \times 10^{-3}$ & 180 & 100 & 72 & 43 & 28 & 0 \\
\hline $15 \% \mathrm{Ni} / \mathrm{COPcomm}$ IIW & $1.61 \times 10^{-7}$ & $2.78 \times 10^{-5}$ & 120 & 36 & 2.4 & Trace & 31.6 & 0.9 \\
\hline Raney Nickel & $2.01 \times 10^{-7}$ & $5.91 \times 10^{-6}$ & 120 & 82 & 5.6 & Trace & 77.1 & 0.24 \\
\hline COPcomm & - & - & 180 & Trace & 0 & 0 & 1.4 & 0 \\
\hline Blank & - & - & 180 & 0 & 0 & 0 & 1.6 & 0 \\
\hline
\end{tabular}

Reaction conditions: $T=599 \mathrm{~K}, 34 \pm 2 \mathrm{mg}$ catalyst, $187 \mathrm{mg}$ TOFA, $155 \mathrm{mg}$ formic acid, $6.2 \mathrm{~g} \mathrm{H}_{2} \mathrm{O}$

${ }^{\mathrm{a}}$ Initial rate (mol.min ${ }^{-1}$ ) based on rate of formation hydrocarbon (deoxygenation product)

${ }^{\mathrm{b}}$ Specific rate $=$ initial rate or hydrocarbon formation/mass of metal loaded into the reactor

${ }^{\mathrm{c}} \mathrm{C} 5-\mathrm{C} 20$ hydrocarbon

d n-heptadecane

${ }^{\mathrm{e}}$ stearic acid

f octadecanol 
et al. could be attributed to factors such the use of $\mathrm{H}_{2}$ donor and the variations in the textural and catalytic properties of catalyst used (Table 2) [18, 19].

\subsection{Hydrocarbon selectivity of supported Pd and Ru catalysts upon hydrothermal deoxygenation of TOFA}

To further evaluate the activity and selectivity of Pd- and Rubased catalysts, we evaluated the effect of batch holding time upon TOFA deoxygenation with $2.5 \mathrm{wt} \%$ aqueous formic acid at $599 \mathrm{~K}$ using two representative catalysts $5 \% \mathrm{Pd} / \mathrm{CSigma}$ and $5 \% \mathrm{Ru} / \mathrm{CSigma}$, respectively. The results of batch holding time on product composition presented in Fig. 1a, b clearly confirmed the catalytic superiority of the Pd-based catalysts over the Ru-based catalysts. With the former producing up to $97 \mathrm{wt} \%$ total hydrocarbon in $60 \mathrm{~min}$ and, in contrast, for the later catalyst, a reaction time of $240 \mathrm{~min}$ was needed to reach a comparable hydrocarbon yield (95 wt \%), (Fig. 1a, b). Furthermore, Fig. 1c and d show n-paraffin selectivity (nheptadecane/total hydrocarbon (\%)) as a function of total hydrocarbon yield for the two representative catalysts. From the selectivity trends, it is clearly seen that, the selectivity to decarboxylation product (n-heptadecane) is highest for $5 \% \mathrm{Pd} /$ CSigma and close to $90-93 \%$ irrespective of total hydrocarbon yield. In contrast for $5 \% \mathrm{Ru} / \mathrm{CSigma}$, $\mathrm{n}$-heptadecane was between 58 and $62 \%$ at comparable total hydrocarbon yield. The reduced n-heptadecane selectivity observed for $5 \% \mathrm{Ru} / \mathrm{CS}$ igma could be attributed to a deoxygenation mechanism comprising of decarboxylation and cracking reactions, whereas for 5\% Pd/ CSigma, a decarboxylation mechanism was exclusively followed (see, section 3.3). Furthermore, from the plots of liquid organic product distribution presented in Fig. 2, it is also clear that for $5 \% \mathrm{Pd} / \mathrm{CS}$ igma catalyst, heptadecane was the main deoxygenation product (yields 81-95 wt\%), whereas heptadecane yield was only $19-58 \mathrm{wt} \%$ (58-61\% selectivity) over the 5\% $\mathrm{Ru} / \mathrm{CSigma}$ catalyst despite the comparable total hydrocarbon yields. A similar trend in the product distribution was also observed for the less active $10 \% \mathrm{Pd} / \mathrm{CO} 850$ and $5 \% \mathrm{Ru} /$ COPcomm catalysts (Fig. 2) in agreement with the influence of metal particle properties on fatty acid deoxygenation. For both Ru- and Pd-based catalysts, on the basis of TOFA, the yield of liquid organic product was in the range of 75-82 $\mathrm{wt} \%$ at full conversion of oxygenated molecules; while, $\mathrm{CO}_{2}$, $\mathrm{H}_{2}$, and trace amounts of C1-C4 hydrocarbons were detected as the main components in the gaseous reaction products. It is also important to highlight that, for both catalysts, saturated nparaffinic hydrocarbons were formed as major products (5895\%), while trace amounts of cycloparaffins, iso-paraffinic and olefines (less than $2 \mathrm{wt} \%$ ) were also detected for Ru catalysts, but no aromatics, and oligomeric products were detected in the reaction product mixture, confirming the suitability of such catalysts for producing fuel range synthetic hydrocarbons from fats and oils under hydrothermal conditions in the presence of aqueous formic acid (Fig. 2).
Fig. 1 Composition of liquid products (wt\%) as a function of batch holding time for a $5 \% \mathrm{Pd} /$ CSigma and $\mathbf{b} 5 \% \mathrm{Ru} / \mathrm{CSigma}$ catalysts, and n-heptadecane selectivity (n-heptadecane/total hydrocarbon (\%)) as a function of total hydrocarbon (deoxygnation product) yield for $\mathbf{c} 5 \% \mathrm{Pd} /$ CSigma and d 5\% Ru/CSigma catalysts. Reaction conditions: $T$ $=599 \mathrm{~K}, 34 \pm 2 \mathrm{mg}$ catalyst, $187 \mathrm{mg}$ TOFA, $155 \mathrm{mg}$ formic acid, $6.2 \mathrm{~g} \mathrm{H}_{2} \mathrm{O}$
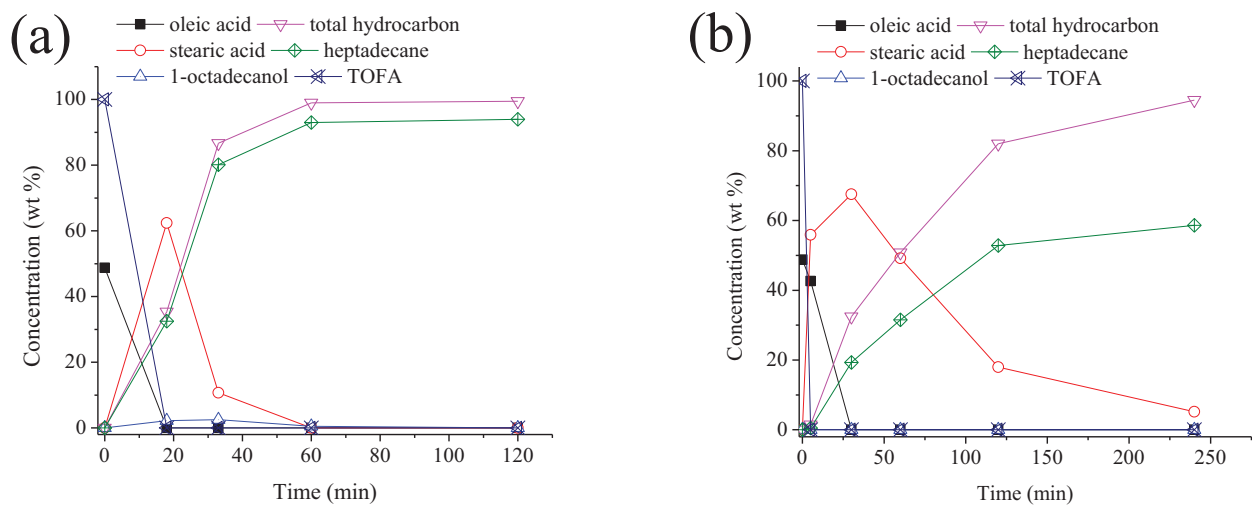

(c)

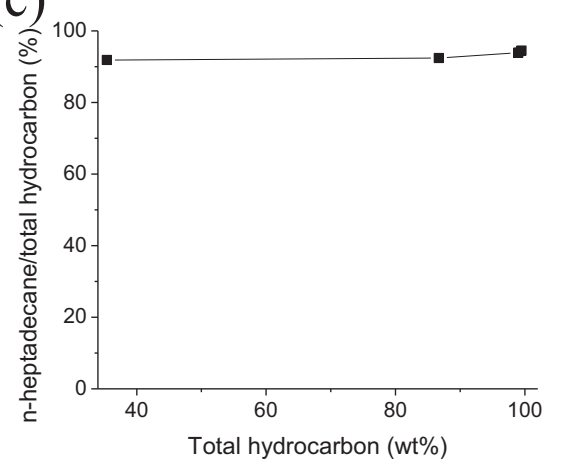

(d)

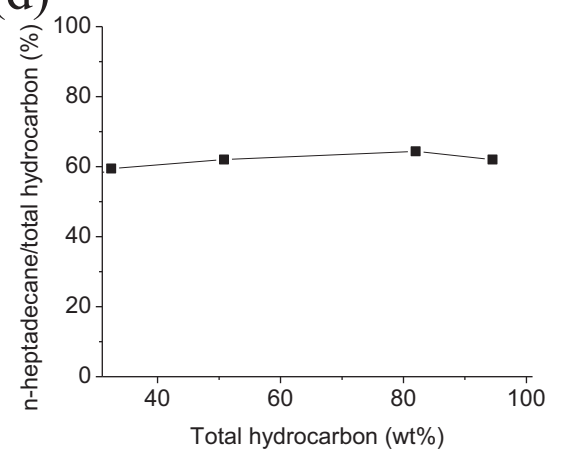


Fig. 2 Composition (wt\%) of liquid range organic products obtained with the Pd and $\mathrm{Ru}$ catalysts upon hydrothermal deoxygenation at $120 \mathrm{~min}$ in the presence of $155 \mathrm{mg}$ formic acid. Reaction conditions: $T=599 \mathrm{~K}$, $34 \pm 2 \mathrm{mg}$ catalyst, $187 \mathrm{mg}$ TOFA, $155 \mathrm{mg}$ formic acid, $6.2 \mathrm{~g}$ $\mathrm{H}_{2} \mathrm{O}$

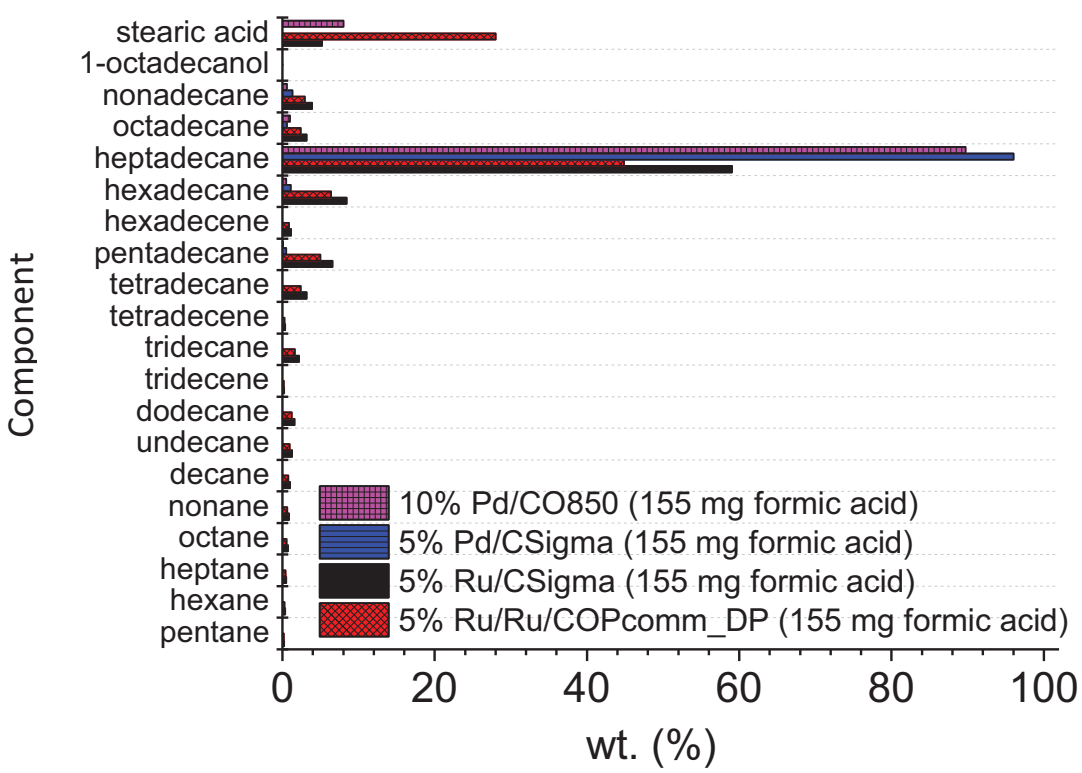

Overall, the observed activity and selectivity trends in Figs. 1 and 2 suggested that for Ru-based catalysts, TOFA deoxygenation proceeds via a combination of hydrogenation, decarboxylation, cracking, and isomerization reactions, whereas for Pd catalysts, deoxygenation takes place selectively through hydrogenation followed by decarboxylation (see, section 3.3). In other words, Ru catalysts directly produced a mixture of diesel range C5-C18 hydrocarbons, while Pd catalysts selectively produced $n$-heptadecane under identical reaction conditions. Experiments with saturated substrates such as stearic acid and glyceryl tristearate without added formic acid also produced identical results confirming the catalytic potential of nanoparticles of Pd- and Ru-supported carbons upon production of synthetic hydrocarbons under hydrothermal conditions (see, section 3.5, Fig. 5).

\subsection{Effect of formic acid concentration upon hydrothermal deoxygenation}

In order to investigate the influence of formic acid concentration on TOFA deoxygenation, catalytic experiments were also conducted with varying amounts of formic acid (wt\%) using $5 \% \mathrm{Pd} / \mathrm{CSigma}$ and $5 \% \mathrm{Ru} / \mathrm{CSigma}$ as the reference catalysts. The effect of aqueous formic acid concentration on TOFA conversion plotted in Fig. 3a shows that under optimized conditions, $100 \%$ TOFA conversions could be reached with formic acid concentration between 2.5 and $7.5 \mathrm{wt} \%$, which was consistent with the formation of adequate in-situ hydrogen for the saturation of fatty acid olefinic bonds. Even so, an unusually high TOFA conversion (49\%) could be achieved even without formic acid addition for 5\% Pd/CSigma (Fig. $3 a)$. In contrast for the $5 \% \mathrm{Ru} / \mathrm{CS}$ igma catalyst, TOFA conversion reached $100 \%$ irrespective of formic acid concentration (Fig. 3a).
In terms of product distribution (or selectivity), an interesting trend could be observed for the $5 \% \mathrm{Pd} / \mathrm{CSigma}$ catalyst with respect to total hydrocarbon and heptadecane yield showing an increasing trend up to $2.5 \mathrm{wt} \%$ formic acid after which it decreased, Fig. 3b. When the amount of formic acid was increased beyond $2.5 \mathrm{wt} \%$, heptadecane/hydrocarbon yield decreased while the yield of 1-octadecanol and octadecane (C18 hydrogenation products) increased reaching 68\% and $2 \%$ respectively for $7.5 \mathrm{wt} \%$ formic acid. This observation was most likely associated with the shifting of deoxygenation mechanism from decarboxylation to hydrodeoxygenation at 5-7.5\% formic acid and good agreement with the $\mathrm{H}_{2}$ partial pressure dependent deoxygenation mechanism for Pd-based catalysts [15]. The reduced yield of deoxygenation product with increased formic acid concentration was consistent with the reduced decarboxylation rates at enhanced $\mathrm{H}_{2}$ partial pressure (Fig. 3b) $[15,16]$; while the formation of hydrogenation products (stearic acid and heptadecane) even without formic acid addition for $5 \% \mathrm{Pd} / \mathrm{CS}$ igma catalyst was consistent with the high TOFA conversion (49\%) and the trends reported in literature, whereupon the carbon support also acted as a source for in-situ hydrogen production by aqueous phase reforming, gasification, and water-gas shift-type reactions $[23,24,33$, 34]. Scheme 1 summarizes the different reactions responsible for in-situ hydrogen production, during hydrothermal deoxygenation of fatty acids and their derivatives in the presence of formic acid [23, 24, 33, 34].

In contrast, $5 \% \mathrm{Ru} / \mathrm{C}$ catalyst produced a mixture of diesel range $\mathrm{C} 5-\mathrm{C} 18$ paraffinic hydrocarbons via decarboxylation and cracking reactions irrespective of the formic acid concentration (Fig. 3c). The slight decrease in hydrocarbon yields observed with $5 \mathrm{wt} \%$ and $7.5 \mathrm{wt} \%$ formic acid concentrations was in agreement with the negative effect of increased reaction pressure on deoxygenation activity under hydrothermal 
Fig. 3 Effect of formic acid concentration on a TOFA conversion and $\mathbf{b}, \mathbf{c}$ the distribution of liquid range products b $5 \% \mathrm{Pd} / \mathrm{CSigma}$ and $\mathbf{c}$ $5 \% \mathrm{Ru} / \mathrm{CSigma}$ during hydrothermal deoxygenation of TOFA under optimized conditions. Reaction conditions: $T=599 \mathrm{~K}$, $34 \pm 2 \mathrm{mg}$ catalyst, $187 \mathrm{mg}$ TOFA, and $6.2 \mathrm{~g} \mathrm{H}_{2} \mathrm{O}$; time $=$ $120 \mathrm{~min}(5 \% \mathrm{Pd} / \mathrm{CSigma})$ and $240 \mathrm{~min}$ (5\% Ru/CSigma)

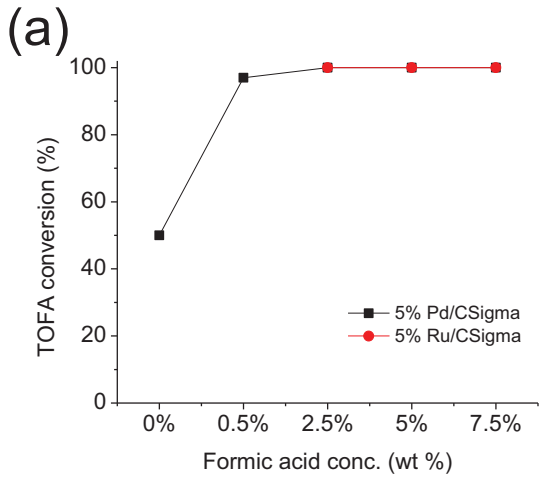

(b)

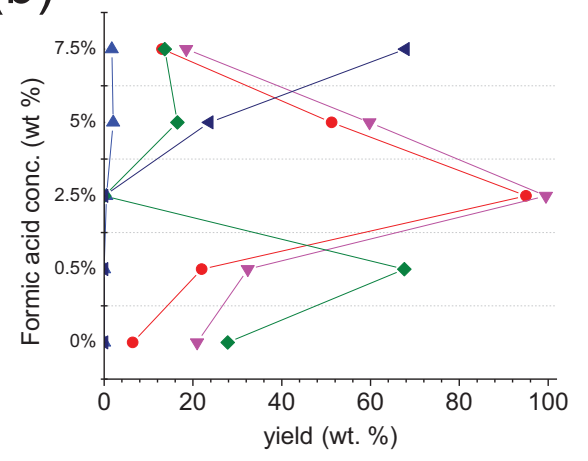

(c)

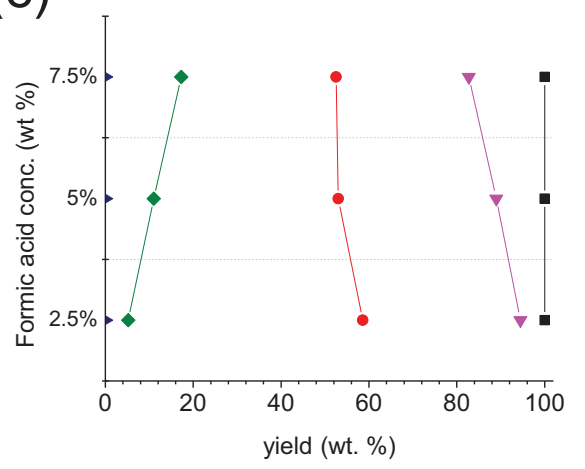

conditions. Although less active, the home-made $\mathrm{Pd}$ and $\mathrm{Ru}$ catalysts (10\% Pd/CO850_DP and 5\% Ru/COPcomm_DP), based on deposition precipitation technique, also produced identical results (data not shown) in agreement with the effects of hydrogen partial pressure upon reaction mechanism (the reduced catalytic performance of home-made catalysts could be attributed to the poor dispersion and active metal area of these catalysts, Table 2). From these results, it can be concluded that the Ru-based catalysts produced a mixture of C5-C18 paraffins through a combination of decarboxylation and cracking reactions, irrespective of the formic acid concentration with heptadecane as the main product (Scheme 2). In contrast, for Pd-based catalysts, the reaction mechanism was dependent on formic acid concentration (or hydrogen partial pressure), producing decarboxylation product (heptadecane) as the main product with formic acid concentration up to 2.5 $\mathrm{wt} \%$, while at 5-7.5 wt\% formic acid, a hydrodeoxygenation/ hydrogenation mechanism was favored producing $\mathrm{C} 18$ deoxygenation products 1-ocatdecanol and octadecane (Scheme 2).

\subsection{Influence of reaction temperature and kinetic analysis}

To further evaluate the activity of Ru-, and Pd-supported carbon catalysts upon hydrothermal deoxygenation of TOFA, temperature-dependent kinetic studies were also conducted with $2.5 \%$ aqueous formic acid using the commercial $5 \%$ $\mathrm{Pd} / \mathrm{CS}$ igma and $5 \% \mathrm{Ru} / \mathrm{CSigma}$ as the representative catalysts. It should also be noted that the yield of deoxygenation products (hydrocarbons) were only used for reaction kinetics analysis, as the conversion of TOFA also includes the
Scheme 1 Plausible reactions responsible for the in-situ $\mathrm{H}_{2}$ production during hydrothermal deoxygenation of fatty acids and fatty acid derivatives in the presence of aq. formic acid

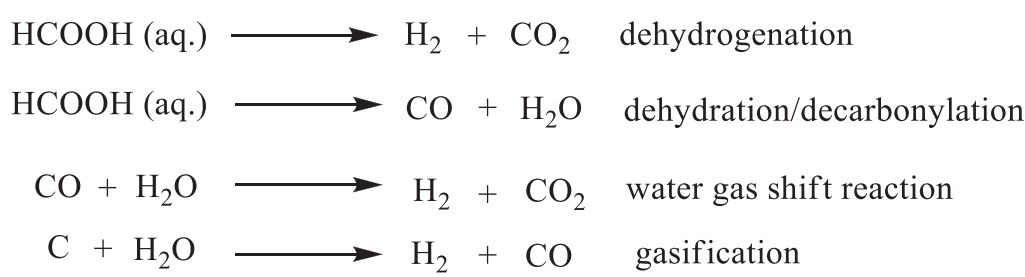

$\mathrm{C}=$ hydrocarbon, alcohol or active carbon

$$
\left.\begin{array}{l}
\mathrm{C}_{3} \mathrm{H}_{8} \mathrm{O}_{3}+3 \mathrm{H}_{2} \mathrm{O} \longrightarrow 7 \mathrm{H}_{2}+3 \mathrm{CO}_{2} \\
\mathrm{CH}_{3} \mathrm{OH}+\mathrm{H}_{2} \mathrm{O} \longrightarrow 3 \mathrm{H}_{2}+\mathrm{CO}_{2}
\end{array}\right\} \text { aqueous phase reforming }
$$


Scheme 2 Reaction network for the formation of the deoxygenation products from hydrothermal deoxygenation of unsaturated fatty acids and fatty acid derivatives in the presence of $\mathrm{Ru}$ and Pd catalysts.

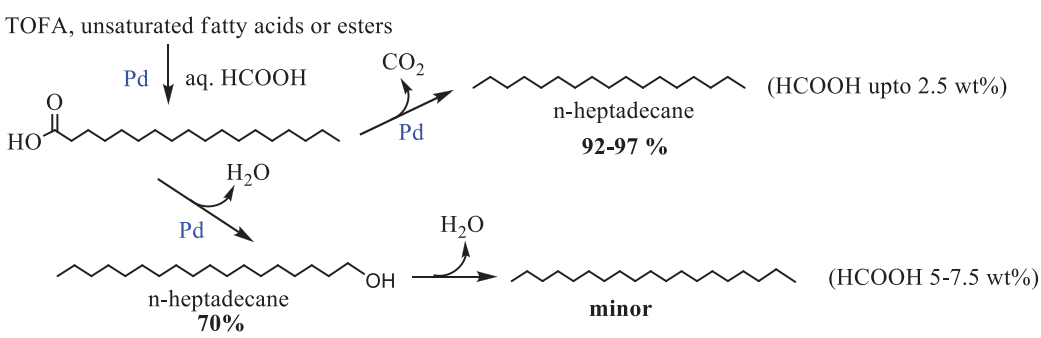

Hydrothermal deoxygenation over Ru-based catalysts

TOFA, unsaturated fatty acids or esters

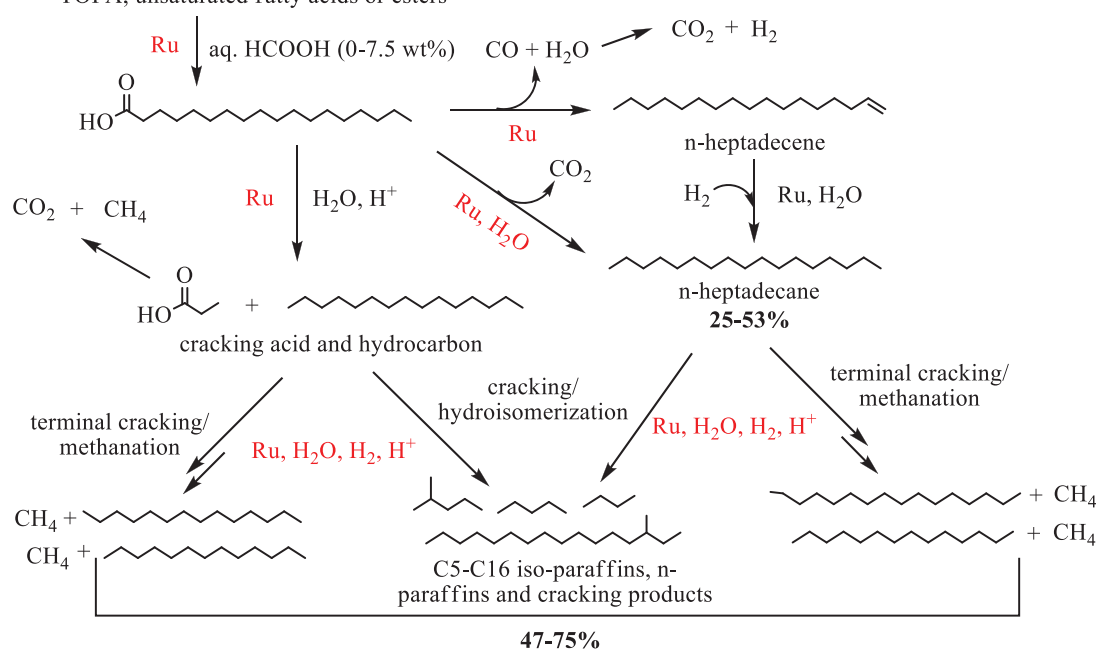

hydrogenation product such as oleic and stearic acid (a oxygenated product). Besides, the dehydrogenation of formic acid and hydrogenation of TOFA olefinic bonds are very fast and, rapidly proceeds during the initial heat up period, even without addition of the active Pd and Ru catalysts.

Figure 4a shows the influence of reaction temperature on the total hydrocarbon yield upon TOFA hydrothermal deoxygenation in the temperature range $569-599 \mathrm{~K}$ and in the presence of $2.5 \mathrm{wt} \%$ aqueous formic acid (optimum conditions for hydrocarbon production). The observed trend was consistent with the enhanced rates of formic acid dehydrogenation,
TOFA hydrogenation, and stearic acid deoxygenation with increasing reaction temperature and, in good agreement with the reactivity trends reported in literature upon hydrothermal deoxygenation/decarboxylation of fatty acids $[18,19,30]$. The temperature dependent kinetic parameters such as $k_{\mathrm{HC}}$ (rate constant of deoxygenation), $k_{n-\mathrm{C} 17}$ (rate constant of decarboxylation), $k_{n-\mathrm{C} 17} / k_{\mathrm{HC}}$ (ratio between the rate constant of deoxygenation to decarboxylation), the apparent activation energy $\left(E_{\mathrm{a}}\right)$ and the pre-exponential factor (A) for TOFA hydrothermal deoxygenation over $5 \% \mathrm{Pd} / \mathrm{CSigma}$ and $5 \% \mathrm{Ru} /$ CSigma catalysts are summarized in Table 4. Furthermore, the
Table 4 Calculated kinetic parameters for formic acidassisted TOFA deoxygenation over $5 \% \mathrm{Pd} / \mathrm{CSigma}$ and $5 \% \mathrm{Ru} /$ CSigma

\begin{tabular}{llllllr}
\hline Catalyst & $\begin{array}{l}T \\
(\mathrm{~K})\end{array}$ & $\begin{array}{l}{ }_{\mathrm{a}} k_{\mathrm{HC}} \\
\left(\mathrm{min}^{-} 1\right)\end{array}$ & $\begin{array}{l}\mathrm{b}_{k-\mathrm{C} 17} \\
\left(\mathrm{~min}^{-} 1\right)\end{array}$ & $\begin{array}{l}\mathrm{c}_{k-\mathrm{C} 17} / \\
k_{\mathrm{HC}}\end{array}$ & $\begin{array}{l}\text { Activation energy }(\mathrm{kJ} / \\
\mathrm{mol})\end{array}$ & ${ }^{\mathrm{e}} \mathrm{A}\left(\mathrm{h}^{-1}\right)$ \\
\hline $5 \%$ & 569 & 0.0044 & 0.0042 & 0.97 & $134.44 \pm 31.36$ & $1.12 \times$ \\
$\mathrm{Pd} /$ CSigma & 589 & 0.0091 & 0.0084 & 0.93 & & $10^{12}$ \\
& 599 & 0.0196 & 0.0182 & 0.92 & & $4.35 \times$ \\
$5 \%$ & 569 & 0.0024 & 0.0014 & 0.6 & $148.92 \pm 3.66$ & $10^{10}$ \\
$\mathrm{Ru} /$ CSigm- & 589 & 0.00673 & 0.0043 & 0.63 & & \\
$\mathrm{a}$ & 599 & 0.01132 & 0.0061 & 0.53 & & \\
\hline
\end{tabular}

${ }^{\text {a }}$ Pseudo $1^{\text {st }}$ order rate constant for deoxygenation based on initial rate of formation hydrocarbons

${ }^{\mathrm{b}}$ Pseudo $1^{\text {st }}$ order rate constants for decarboxylation based initial rate of formation of n-heptadecane

${ }^{\mathrm{c}}$ Ratio between the rate constant of deoxygenation to decarboxylation

${ }^{\mathrm{d}}$ Apparent activation energy for deoxygenation

${ }^{\mathrm{e}}$ Pre-exponential factor for deoxygenation 
Fig. 4 a Total hydrocarbon yield (wt $\%$ ) as a function of reaction temperature for Pd- and Ru-based catalysts (reaction conditions: time $=30 \mathrm{~min}, 34 \pm 2 \mathrm{mg}$ catalyst, $187 \mathrm{mg}$ TOFA, $155 \mathrm{mg}$ formic acid, $6.2 \mathrm{~g} \mathrm{H}_{2} \mathrm{O}$ ) and b Arrhenius plots $\left(\ln \left(k_{\mathrm{HC}}\right)\right.$ vs. $\left.1 / \mathrm{T}\right)$ for $5 \% \mathrm{Pd} /$ CSigma and $5 \% \mathrm{Ru} / \mathrm{CSigma}$ (a)

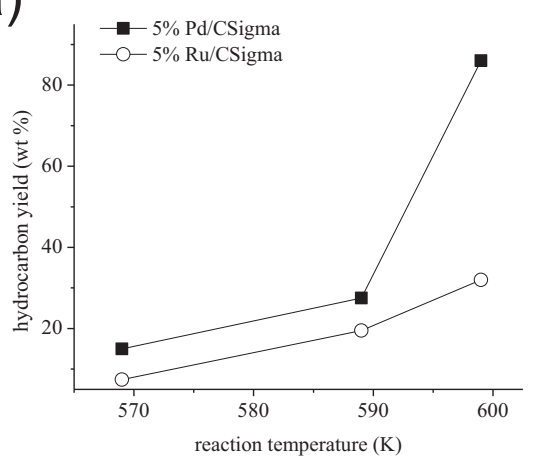

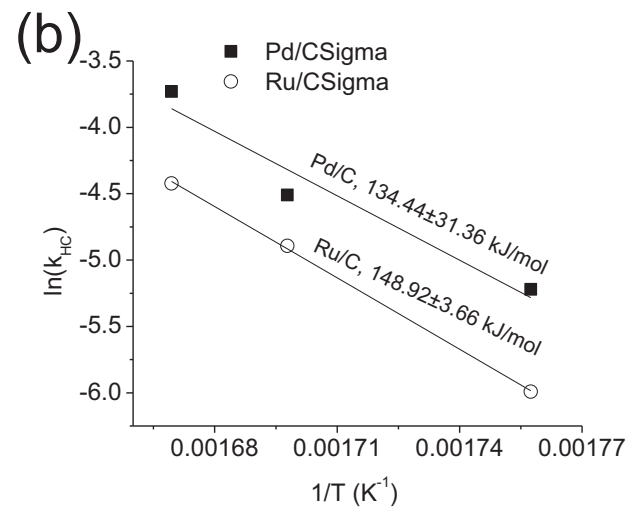

$k_{\mathrm{HC}}$ values estimated for the two catalysts is clear that the rate limiting deoxygenation step showed an Arrhenius type behavior similar to the reports in literature for the various carbonbased catalysts, (Fig. 4b) [18-25]. Using these plots, the apparent activation energy $\left(E_{\mathrm{a}}\right)$ of the reaction (deoxygenation step) was estimated to be $134.44 \pm 31.36 \mathrm{~kJ} / \mathrm{mol}$ and $148.92 \pm$ 3.66 for $5 \% \mathrm{Pd} / \mathrm{CSigma}$ and $5 \% \mathrm{Ru} / \mathrm{CSigma}$, respectively (Table 4), in agreement with the superior deoxygenation activity of the Pd-based catalysts [35]. The activation energy values obtained in this work were also higher than those reported by Savage et al. for Pt/C catalyst $(79 \pm 5 \mathrm{~kJ} / \mathrm{mol})$ upon palmitic acid hydrothermal decarboxylation, which could be attributed to both the use of less active metals as well as the use of less reactive C18 fatty acids as feedstock [18, 19]. Nevertheless, the observed values of apparent activation energy $\left(E_{\mathrm{a}}>25 \mathrm{~kJ} / \mathrm{mol}\right)$ indicated a kinetically controlled reaction free from inter-particle diffusion and external mass transfer limitations [36]. The absence of pore-diffusion and interphase mass transfer observation was also consistent with the, Weisz-Prater parameter $\left(C_{\mathrm{WP}}\right)<<1$ obtained for the catalytic systems under experimental conditions [18, 19]. A comparison of the $k_{n-\mathrm{C} 17}$ and $k_{n-\mathrm{C} 17} / \mathrm{k}_{\mathrm{HC}}$ ratio for the two catalysts in Table 4, further confirmed the difference in deoxygenation mechanism of TOFA/steric acid for the Pd and Ru-based catalysts, the comparable $k_{n-\mathrm{C} 17}$ and $k_{\mathrm{HC}}$ values, and $k_{n-\mathrm{C} 17} / k_{\mathrm{HC}}$ ratio close to $\sim 1(0.83-0.92)$ for $5 \% \mathrm{Pd} / \mathrm{CSigma}$, indicate a deoxygenation mechanism deoniated by selective decarboxylation of saturated $\mathrm{C} 18$ fatty acids, in contrast to the low $k_{n-\mathrm{C} 17} / k_{\mathrm{HC}}$ ratios observed for $5 \% \mathrm{Ru} / \mathrm{CS}$ igma indicated a reaction network comprising of decarboxylation, cracking, gasification, and isomerization reactions [35, 37].

\subsection{Influence of different feedstocks, catalyst reuse, and deoxygenation mechanism}

Motivated by the promising results obtained upon hydrothermal decarboxylation/deoxygenation of TOFA, to evaluate the substrate scope, further experiments were conducted with glycerol tristearate, steric acid, rapeseed oil, sunflower oil, rapeseed methyl esters and rapeseed fatty acids under optimized reaction conditions, the results of which are presented in Fig. 5. From the data presented in Fig. 5, it can be seen that the reported hydrothermal system comprising trace amounts of formic acid as $\mathrm{H}_{2}$ source and $\mathrm{Pd}$ /carbon as catalyst, was capable of efficiently converting different unsaturated C18 feedstocks under identical reaction conditions selectively producing n-heptadecane. The Ru-based catalysts also produced similar results with different C18 feedstocks (rapeseed oil, rapeseed methyl esters, and glycerol tristearate) producing a mixture of C5-C18 paraffinic hydrocarbons (Fig. 5). However, the deoxygenation of glycerol tristearate without added formic acid proceeded at a faster rate over $\mathrm{Ru} /$ CSigma, than the $\mathrm{Pd} / \mathrm{CS}$ igma catalyst, indicating formic acid dehydrogenation to the limiting step for deoxygenation of
Table 5 TOFA conversion and product yield for reused catalysts upon hydrothermal deoxygenation of at $599 \mathrm{~K}$

\begin{tabular}{lllll}
\hline Catalyst & Conversion $(\%)$ & Time & \multicolumn{2}{l}{ Yield (wt \%) } \\
\cline { 4 - 5 } & & $(\mathrm{min})$ & Hydrocarbon & Steric acid \\
\hline $5 \% \mathrm{Pd} / \mathrm{CS}$ Sigma spent & 100 & 120 & 49.5 & 50.5 \\
$5 \% \mathrm{Pd} / \mathrm{CS}$ spent* & 100 & 120 & $>99$ & 0 \\
$5 \% \mathrm{Ru} / \mathrm{CS}$ igma spent & 100 & 180 & 32 & 68 \\
$10 \% \mathrm{Pd} / \mathrm{CDP}$ spent & 100 & 180 & 87 & 13 \\
\hline
\end{tabular}

*spent catalyst + recovered aqueous phase

Reaction conditions: $T=599 \mathrm{~K}, 34 \pm 2 \mathrm{mg}$ catalyst, $187 \mathrm{mg}$ TOFA, $155 \mathrm{mg}$ formic acid, $6.2 \mathrm{~g} \mathrm{H}_{2} \mathrm{O}$ 


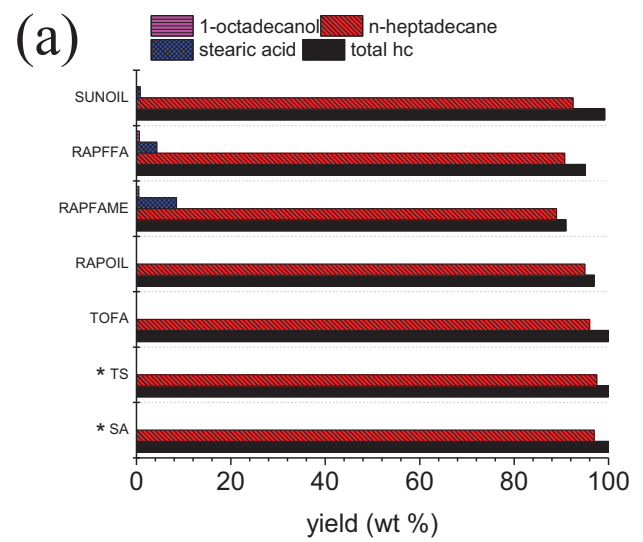

Fig. 5 Composition of liquid organic products obtained with a $\mathrm{Pd} /$ CSigma and $\mathbf{b} \mathrm{Ru} /$ Csigma catalysts. Feedstocks: SA (stearic acid), TS (glycerol tristearate), tall oil fatty acids (TOFA), SUNOIL (sunflower oil), RAP OIL (rapeseed oil), RAPFAME (rapeseed methyl esters), RAPFFA

unsaturated $\mathrm{C} 18$ feedstocks (TOFA, rapeseed oil, and rapeseed methyl esters). This observation suggests the important role of aqueous phase reforming and water gas shift reactions for $\mathrm{H}_{2}$-generation with $\mathrm{Ru}$-based catalysts (Scheme 1).

The stability of the supported carbon catalysts were also investigated conducting reusability tests by re-employing the spent catalyst recovered from hydrothermal reactions, the results of which are also summarized in Table 5. The reusability data presented in Table 5 shows that, upon reuse, there was a significant loss of catalytic/deoxygenation activity for the commercial Pd and Ru catalysts (hydrocarbon yield dropped by ca. $50 \%$ during the 1 st recycle), in contrast to the activity loss of catalysts obtained by deposition precipitation method which was less significant. This activity loss can be primarily attributed to the leaching of metal nanoparticles under the harsh hydrothermal conditions; the improved stability homemade catalysts could be explained in terms of the enhanced nanoparticle support interactions and higher metal loadings. Nevertheless, a detailed discussion on the deactivation/stability of metal-supported carbon catalysts upon hydrothermal deoxygenation of fatty acids (or fatty acid derivatives) is beyond the scope of this study and will be addressed in separate study. Even so, the results obtained herein confirm the versatility of formic acid-aided hydrothermal deoxygenation as efficient method for the production of diesel range synthetic hydrocarbons as well as fatty alcohols in the presence of catalytic amounts Ru- and Pd-supported carbon catalysts.

\section{Conclusions}

In conclusion, hydrothermal hydrodeoxygenation/ decarboxylation in the presence of aqueous formic acid was demonstrated to be a powerful process for producing diesel

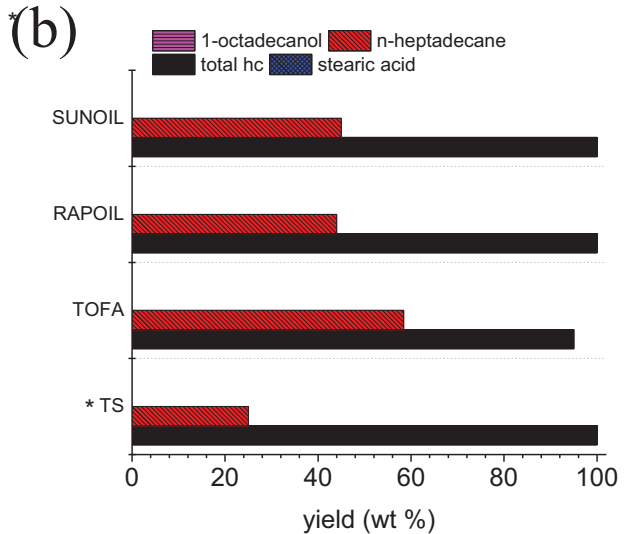

(rapeseed fatty acids). Reaction conditions: $34 \pm 2 \mathrm{mg}$ catalyst, $189 \mathrm{mg}$ feed, $155 \mathrm{mg}$ formic acid (*no formic acid for TS and SA), $6.2 \mathrm{~g} \mathrm{H}_{2} \mathrm{O}$, $599 \mathrm{~K}, 120 \mathrm{~min} \mathrm{Pd} / \mathrm{Csigma}$ and $240 \mathrm{~min} \mathrm{Ru} / \mathrm{Csigma}$

range hydrocarbons and primary alcohols from TOFA and related oligogeneous feedstocks. Using the aforementioned process, hydrocarbon yields up to $99.5 \mathrm{wt} \%$ could be reached over Pd and Ru nanoparticles supported on carbon. The reaction mechanism was mainly influenced by the concentration of formic acid and catalyst type. Kinetic studies showed that the rates of deoxygenation displayed Arrhenius type behavior with an activation energies of $134.44 \pm 31.36$ and $148.92 \pm$ 3.66 for the $5 \% \mathrm{Pd} / \mathrm{CSigma}$ and $5 \% \mathrm{Ru} / \mathrm{CSigma}$ catalysts, respectively. Ru catalysts produced a mixture of C5-C18 paraffinic hydrocarbons via decarboxylation and cracking (up to $58 \mathrm{wt} \% \mathrm{C} 17$ yield and total hydrocarbon yield up to 95 wt $\%)$ irrespective of formic acid concentration. On the contrary, Pd catalysts with $0-2.5 \mathrm{wt} \%$ formic acid produced heptadecane via the decarboxylation pathway, while with 5 $7.5 \%$ formic acid concentration, $\mathrm{C} 18$ deoxygenation products ocatdecanol and octadecane were formed as the main products through the hydrodeoxygenation/hydrogenation mechanisms.

Acknowledgments Bio4Energy programme, Kempe Foundations (Kempe stiftelserna), and Wallenberg Wood Science Center (WWSC) are gratefully acknowledged. This work is also a part of the Johan Gadolin Process Chemistry Centre.

Funding Open access funding provided by Umea University.

Open Access This article is licensed under a Creative Commons Attribution 4.0 International License, which permits use, sharing, adaptation, distribution and reproduction in any medium or format, as long as you give appropriate credit to the original author(s) and the source, provide a link to the Creative Commons licence, and indicate if changes were made. The images or other third party material in this article are included in the article's Creative Commons licence, unless indicated otherwise in a credit line to the material. If material is not included in the article's Creative Commons licence and your intended use is not permitted by statutory regulation or exceeds the permitted use, you will need to obtain permission directly from the copyright holder. To view a copy of this licence, visit http://creativecommons.org/licenses/by/4.0/. 


\section{References}

1. Climent MJ, Corma A, Iborra S (2014) Conversion of biomass platform molecules into fuel additives and liquid hydrocarbon fuels. Green Chem 16:516-547

2. Konwar LJ, Kataki R, Mikkola J-P, Bordoloi N, Saikia R, Chutia RS (2018) Side-streams from bioenergy and biorefinery complexes as a resource for circular bio-economy. Chapter 3, In: Waste Biorefinery: potential and perspectives 1st Edition, Ed. by Pandey A, Bhaskar T, Mohan SV, Lee D-J, Khanal SK, Elsevier, Amsterdam

3. Taylor DC; Smith MA; Fobert P; Mietkiewska E; Weselake RJ (2011) Plant systems-metabolic engineering of higher plants to produce bio-industrial oils In: M. Moo-Young (Ed.). Comprehensive biotechnology, Vol. 4(2), Elsevier, Amsterdam/Boston, 67-85.

4. Knothe G, Karhl J, Van Gerpen J (eds) (2005) The biodiesel hand book. AOCS Press, Champaign, pp 1-286

5. Huber GW, Iborra S, Corma A (2006) Synthesis of transportation fuels from biomass: chemistry, catalysts, and engineering. Chem Rev 106(9):4044-4098

6. Fazal MA, Haseeb ASMA, Masjuki HH (2011) Biodiesel feasibility study: An evaluation of material compatibility; performance; emission and engine durability. Renew Sust Energ Rev 15:1314 1324

7. Aslam Md, Konwar LJ, Sarma AK, Kothiyal NC (2015) An investigation of catalytic hydrocracking of high FFA vegetable oils to liquid hydrocarbons using biomass derived heterogeneous catalysts. J Anal Appl Pyrolysis 115:401-409

8. Koivusalmi E, Jakkula J (2008) Process for the Manufacture of Hydrocarbons, Patent US7459597B2

9. Rantanen L, Linnaila R, Aakko P, Harju T (2005) NExBTLBiodiesel Fuel of the Second Generation. SAE Technical Paper 01:771

10. Sugami Y, Minami E, Saka S (2016) Renewable diesel production from rapeseed oil with hydrothermal hydrogenation and subsequent decarboxylation. Fuel 166:376-381

11. Sotelo-Boyás R, Trejo-Zarraga F, de Jesús Hernández-Loyo F (2012) Hydroconversion of Triglycerides into Ggreen Liquid Fuels. Chapter 8, In Hydrogenation, Ed. by I. Karamé InTech, Rijeka

12. Šimáček P, Kubička D, Šebor G, Pospíšil M (2009) Hydroprocessed rapeseed oil as a source of hydrocarbon-based biodiesel. Fuel 88:456-460

13. Chiappero M, Do PTM, Crossley S, Lobban LL, Resasco DE (2011) Direct conversion of triglycerides to olefins and paraffins over noble metal supported catalysts. Fuel 90:1155-1165

14. Satyarthi JK, Chiranjeevi T, Gokak DT, Viswanathan PS (2013) An overview of catalytic conversion of vegetable oils/fats into middle distillates. Catal Sci Technol 3:70-80

15. Rozmysłowicz B, Mäki-Arvela P, Tokarev A, Leino A-R, Eränen K, Murzin DY (2012) Influence of hydrogen in catalytic deoxygenation of fatty acids and their derivatives over Pd/C. Ind Eng Chem Res 51(26):8922-8927

16. Mäki-Arvela $\mathrm{P}$, Kubickova I, Snåre $\mathrm{M}$, Eränen K, Murzin DY (2007) Catalytic deoxygenation of fatty acids and their derivatives. Energy Fuel 21:30-41

17. Snåre $M$, Kubičková I, Mäki-Arvela $P$, Chichova D, Eränen K, Murzin DY (2008) Catalytic deoxygenation of unsaturated renewable feedstocks for production of diesel fuel hydrocarbons. Fuel 87 : 933-945

18. Fu J, Lu X, Savage PE (2010) Catalytic hydrothermal deoxygenation of palmitic acid. Energy Environ Sci 3:311-317

19. Fu J, Lu X, Savage PE (2011) Hydrothermal decarboxylation and hydrogenation of fatty acids over Pt/C. ChemSusChem 4:481-486
20. Duan P, Bai X, Xu Y, Zhang A, Wang F, Zhang L, Miao J (2013) Catalytic upgrading of crude algal oil using platinum/gamma alumina in supercritical water. Fuel 109:225-233

21. Zhang Z, Chen Z, Gou X, Chen H, Chen K, Lu X, Ouyang P, Fu J (2018) Catalytic decarboxylation and aromatization of oleic acid over $\mathrm{Ni} / \mathrm{AC}$ without an added hydrogen donor. Ind Eng Chem Res 57:8443-8448

22. Miao C, Marin-Flores O, Davidson SD, Li T, Dong T, Gao D, Wang Y, Garcia-Pérez M, Chen S (2016) Hydrothermal catalytic deoxygenation of palmitic acid over nickel catalyst. Fuel 166:302-308

23. Fu J, Shi F, Thompson LT Jr, Lu X, Savage PE (2011) Activated carbons for hydrothermal decarboxylation of fatty acids. ACS Catal 1:227-231

24. Popov S, Kumar S (2015) Rapid hydrothermal deoxygenation of oleic acid over activated carbon in a continuous flow process. Energy Fuels 29(5):3377-3384

25. Hossain MZ, Jhawar AK, Chowdhury MBI, Xu WZ, Wu W, Hiscott DV, Charpentier PA (2017) Using subcritical water for decarboxylation of oleic acid into fuel-range hydrocarbons. Energy Fuel 31(4):4013-4023

26. Gilkey MJ, Xu B (2016) Heterogeneous catalytic transfer hydrogenation as an effective pathway in biomass upgrading. ACS Catal 6(3):1420-1436

27. Vardon DR, Sharma BK, Jaramillo H, Kim D, Choe JK, Ciesielski PN, Strathmann TJ (2014) Hydrothermal catalytic processing of saturated and unsaturated fatty acids to hydrocarbons with glycerol for in situ hydrogen production. Green Chem 16:1507-1520

28. Mao J, Jiang D, Fang Z, Wu X, Ni J, Li X (2017) Efficient hydrothermal hydrodeoxygenation of triglycerides with in situ generated hydrogen for production of diesel-like hydrocarbons. Catal Commun 90:47-50

29. Bulushev DA, Ross JRH (2018) Towards sustainable production of formic acid. ChemSusChem. 11(5):821-836

30. Yu J, Savage PE (1998) Decomposition of formic acid under hydrothermal conditions. Ind Eng Chem Res 37(1):2-10

31. Bi Q-Y, Lin J-D, Liu Y-M, He H-Y, Huang F-Q, Cao Y (2016) Dehydrogenation of formic acid at room temperature: boosting palladium nanoparticle efficiency by coupling with pyridinic-nitrogendoped carbon. Angew Chem Int Ed Eng 55(39):11849-11853

32. Pham T-N, Samikannu A, Rautio A-R, Juhasz KL, Konya Z, Wärnå J, Kordas K, Mikkola J-P (2016) Catalytic hydrogenation of d-xylose over $\mathrm{Ru}$ decorated carbon foam catalyst in a SpinChem ${ }^{\circledR}$ rotating bed reactor. Top Catal 59:1165-1177

33. Xu X, Matsumura Y, Stenberg J, Antal MJ (1996) Carboncatalyzed gasification of organic feedstocks in supercritical water. Ind Eng Chem Res 35(8):2522-2530

34. Hossain MZ, Chowdhury MBI, Jhawar AK, Xu WZ, Charpentier PA (2018) Continuous low pressure decarboxylation of fatty acids to fuel-range hydrocarbons with in situ hydrogen production. Fuel 212:470-478

35. Zhang J, Huo X, Li Y, Strathmann TJ (2019) Catalytic hydrothermal decarboxylation and cracking of fatty acids and lipids over $\mathrm{Ru} /$ C. ACS Sustain Chem Eng 7:14400-14410

36. Konwar LJ, Wärnå J, Mäki-Arvela P, Kumar N, Mikkola J-P (2016) Reaction kinetics with catalyst deactivation in simultaneous esterification and transesterification of acid oils to biodiesel (FAME) over a mesoporous sulphonated carbon catalyst. Fuel 166:1-11

37. Konwar LJ, Mikkola J-P (2020) Effects of carbon support surface chemistry upon metal ( $\mathrm{Pd}, \mathrm{Pt}$ and $\mathrm{Ru}$ ) catalyzed hydrothermal decarboxylation/deoxygenation of triglycerides. Catal Sci Technol Submitted

Publisher's Note Springer Nature remains neutral with regard to jurisdictional claims in published maps and institutional affiliations. 